Brit. J. soc. Med. (1947), 1, 197-208.

\title{
SOCIAL SERVICE FOR A MEDICAL WARD
}

BY

\author{
I. FLORA BECK, A.I.H.A., FRANCES V. GARDNER, M.D.,* AND \\ L. J. WITTS, M.D., F.R.C.P. \\ From the Nuffield Department of Medicine, Radcliffe Infirmary, Oxford
}

On the eve of new legislation which will affect the results of illness for hospital patients, it seems opportune to discuss the present need for an almoner's services on a medical ward and what it is likely to be in the future. In 1943 a study was carried out in this department of a group of patients admitted to a medical ward during a period of six months, and it was concluded that 70 per cent. of the patients required an almoner's supervision or help (Brown and Carling, 1945). Since that date an almoner has been attached as social worker to the department, and her duties have included the social care and supervision of patients while in the ward and after discharge. A further follow-up study has now been carried out in order to find out what difference this has made. The main questions to be answered are: what proportion of medical patients require the services of an almoner, what are the main social problems with which the almoner has to deal, how much almoning time is needed if medical social supervision is to be effective, and how can the almoner's services be integrated most efficiently with those of the medical staff?

\section{MATERIAL}

Collier Ward, whose patients have provided the material for both the studies mentioned here, is in the charge of the Nuffield Professor of Clinical Medicine and is divided into accommodation for ten men and eleven women. The admissions during a period of six months from August, 1941, to January, 1942, had been chosen for the first investigation; for the second one it was decided to study the patients admitted during the twelve months from November, 1943, to October, 1944, and they were followed up between one and two years after their admission to hospital.

In the twelve months under review 355 patients, 180 male and 175 female, were admitted; the ages ranged from 5 to 77 , but the majority were between the ages of 21 and 50. Over 80 per cent. came from Oxford or the surrounding area served by the Radcliffe Infirmary; their social and occupational status varied between wide limits, but, apart from the 10 per cent. who were members of the services, the majority of the men were employed either on agriculture or industrial work such as the war-time adaptation of the motor trade, while more than half the women were housewives. Nearly a third of the patients were admitted with gastro-intestinal complaints, and another large group had diseases of the blood; the average length

* With a grant from the Medical Research Council. 
of stay in hospital was sixteen days. Sixty patients, or just over 17 per cent., died within two years of admission to hospital. Complete records of 257 of the surviving patients were obtained; 183 of them were seen; and reports were received of 74 others. A further eleven patients were known to be alive and working full time, although no detailed information could be obtained about them. Twenty-seven patients could not be traced; eight of these were members of the services, and the rest were evacuees, casual labourers, and others who had left the district.

At the time of the follow-up, 134, or 38 per cent. of the patients, were cured, and 130 , or 37 per cent., were still suffering from the disease which had caused admission; 17 per cent. were dead, and 8 per cent. lost sight of. A review of the activities of the surviving patients provides a less discouraging impression. Although only 38 per cent. of the patients admitted had been cured, 215 , or 60 per cent., had returned to full-time work, $30(8 \cdot 5$ per cent.) were doing part-time work, and only $23(6 \cdot 5$ per cent.) were unable to pursue their usual employment. In about 70 per cent. of the surviving patients the capacity for work was unaltered, though in the remainder it had been reduced as a result of the illness. In only a small proportion of cases was the earning capacity significantly reduced. The review of this group of patients one to two years after in-patient treatment led to revision of the diagnosis in four, and suggestions for further medical treatment or supervision in 31. Twelve patients needed further treatment for their original disease; eight for diseases which had developed since their discharge from hospital; seven were referred to other departments for advice and treatment, and four patients were in need of regular medical supervision.

\section{The Need for Social Service ANd Supervision}

Although it had previously been concluded that 70 per cent. of the patients required an almoner's supervision or help, in the present series the proportion was found to be less; including those who merely needed advice or minor services, only 54 per cent. needed any form of help from the almoner. The two series of patients are, however, not entirely comparable, and the larger proportion of patients in the second series who had relatively short illnesses is probably mainly responsible for the difference.

For a short acute illness, whether the result is fatal or whether recovery is complete, the problem is medical rather than social and it is during a long illness that the almoner's services are most frequently required. Including those whose illness ended fatally, 44 per cent. of the patients were incapacitated for longer than three months, and of these 36 per cent. had serious social problems, whereas similar problems were found only among 13 per cent. of the others. A group of patients with infective hepatitis who were admitted for purposes of medical research presented scarcely any social problems. They had only a short illness and made good recoveries, and most of the civilians would not normally have come into hospital at all. The service patients with infective hepatitis, and other service 
patients with short illnesses who later returned to units, suffered no financial loss through illness, and adequate arrangements were made for their convalescence and general after-care through the normal service channels; only those who were in hospital for a long period and who might need to be discharged from the service on account of their illness needed social supervision from the hospital. Excluding the patients with infective hepatitis and the other short-term service patients, about 60 per cent. of the present series needed some social help or supervision, although only 24 per cent. had serious social difficulties as a result of their illness.

\section{Serious Social Problems Resulting from Illness}

The most serious social and economic problems which patients had to face as a result of illness were caused by loss of wages, by enforced change of employment, or by domestic difficulties, especially the care of young children. Seventy patients (22 per cent.) had problems which fell into one or more of these categories, and ten more had difficulties of various kinds which required detailed assistance or longterm planning and supervision by the almoner.

Financial Problems.-Twenty-four patients (8 per cent.) had financial difficulties serious enough to cause acute anxiety or to require material assistance; all except two of these problems resulted from loss of earning capacity through long illness, while the others were caused by expenses connected with illness. The higher rate of sickness benefit in the proposed new social insurance scheme would have eased but would not completely have removed these problems. Even if sickness benefit may be continued at the full rate for three years, it is still the patients whose illness lasts less rather than more than three months who are likely to benefit most by it. The patients with short periods of incapacity in this series supplemented their sickness benefit with savings, and such temporary difficulties or worries as their sudden drop in income may have caused them were not serious enough to have left much impression on their minds by the time the follow-up was undertaken. A higher rate of sickness benefit would, however, have been a welcome help at the time, and, had it not been for the opportunity to save which full employment and a good general level of wages had given, their need would have been considerably greater.

The patients who had serious financial difficulties had almost all remained off work for three months or longer, and even with higher rates of benefit this would entail a serious drop in the standard of living. A married man with one child would receive $£ 2$ 5s. per week sickness benefit. Even the cow-man who had been getting $£ 4$ per week would have found this difficult to manage on for a long period, while the proportionate drop in income would be more serious still for the teacher whose salary was normally $£ 500$ per annum and who lost three terms' salary through illness, or for the sheet metal worker who had been earning $£ 8$ per week and had to remain off work for six months. Seven patients in our series had to be referred to public assistance, and with a higher rate of sickness benefit such a course 
could no doubt have been avoided. This would have been a great advantage on psychological grounds; but the public assistance allowance, which took account of variations in rent, left them, in fact, rather better off materially than they would be with the new benefits.

The amount of material assistance which the almoner was able to give the patients who were in financial difficulties was limited. Grants of various sorts were obtained from charitable sources to cover emergency needs or to enable patients who were living on a reduced income to obtain extras, and arrangements were made for the patients already mentioned to apply for public assistance. The almoner's main task was, however, to make sure that patients received all the statutory benefits to which they were entitled, and especially to discuss with the patients or their relatives how their difficulties could best be met and to help them to plan ahead. Often it was found that both the wage earners and their wives were worried but did not know what to expect and clung rather vaguely to the hope that " they would manage somehow." The almoner, who was in close touch with the medical staff and could get from them an approximate idea of the prognosis at an early stage, was able to foresee the future difficulties more clearly than the patients and could help them to plan constructively. The results suggested that this form of social service was quite as important as the provision of material help, and there is no reason to expect that the need for it in the future will be any less than it has been in the past.

Employment.-Thirty-two patients (10 per cent.) required assistance in changing their employment, and twenty more (6.5 per cent.) adjusted or changed their employment without assistance. The Ministry of Labour's interim scheme for resettlement of disabled persons, precursor of the Disabled Persons Employment Act, was in force at the time, and extensive use was made of it. Employment conditions were exceptional: the demand for labour of any sort was acute and National Service restrictions were extensive. It happened, therefore, that the Ministry of Labour's special machinery was often used rather as a convenient method of securing release from a previous job than as a means of finding a new one. Thus, although twenty-nine patients required medical evidence before they could be released from their previous employment, only seven had their new work found for them by the Ministry of Labour, and the rest found jobs for themselves. This situation has already changed, and although registration under the Disabled Persons Act may help patients to compete in an open market, the difficulties of finding work which is adequately paid but still within their physical limitations are likely to increase.

The almoner kept in close touch with the local Disablement Rehabilitation Officers, and repeated consultations with them were sometimes necessary. When suitable work of a slightly different kind or under modified conditions could be provided by previous employers, patients were usually able to arrange this for themselves, but they were advised to get in touch with the almoner in case of difficulty, and occasionally her assistance was required. 
A recommendation for change or adjustment of employment is a medical matter, and any decision about it must rest with the medical staff, but for many of these patients no action would have been taken by the hospital if the question had not first been raised by the almoner. This does not imply that the medical staff failed to take into account the type of work which patients had been doing or the need to alter it when necessary, but rather that house physicians were apt to think that telling a patient to take a different job was quite sufficient. As patients themselves usually agree to such suggestions without further comment, whether they expect to be able to put them into practice or not, some experience of what usually happens to such patients later is required before the need for more positive action is realized. The previous follow-up provided examples of patients who had found the greatest difficulty in obtaining suitable work by themselves, and of others who were not employed but could and should have been trained for some work within their range of physical activity. Patients should be encouraged to make their own arrangements when there are reasonable grounds for expecting them to succeed, but the results of their own efforts should be ascertained in case further help is needed. Present experience confirmed the impression that, when patients are referred to the Ministry of Labour for rehabilitation, the hospital must continue supervision at least until the patient has returned to work.

Domestic Problems. - The difficulty of caring for patients' homes and families while they were in hospital, or of looking after them at home when this was necessary, was mainly solved by the patients themselves with the help of relatives, friends, and neighbours. Often this caused inconvenience and, if a wage-earner had to remain at home, loss of income. Housewives were apt to worry about how their families were managing without them, or to feel disturbed at "putting upon" other people, but the problem caused serious difficulties only for thirteen (4 per cent.) of the patients, of whom nine were housewives with young children. Neither of the two patients whose children had to be admitted to public assistance nurseries regarded this as satisfactory, and another young woman discharged herself against advice rather than consent to such an arrangement; some prejudice against letting the children go away from home would have been likely in any case, but it would undoubtedly have been lessened if application through a relieving officer had not been necessary. Exhaustive attempts were made to obtain domestic help for a patient with cirrhosis of the liver whose need was especially acute, but without success. Housewives who have always been accustomed to doing their work themselves do not welcome the presence of a stranger in the home, and any system of home helps is likely to have disadvantages, but there is scope for a much greater extension of this service; some local authorities already provide home helps, but it is encouraging that it is proposed to include such facilities in the new health service, and it is to be hoped that all local authorities will in future make full use of their powers in this connexion.

Personal Problems._Almost all the major social problems and many of the less serious ones caused either immediate anxiety or apprehension about the future; 
some made it necessary for patients to make difficult or unpleasant decisions. Illness of a wage-earner or of a housewife might, for different reasons, throw a strain on the normal family relationships and cause friction or misunderstandings, and when dealing with material difficulties the almoner had to take these personal problems into account. Fourteen of the patients had personal problems resulting from their illness which seemed serious enough to be specially noted. One, a married woman who was found to have a luetic infection, required much encouragement and help in dealing with a difficult domestic situation and in persisting with treatment, although no material assistance was required.

\section{Subsidiary Forms of Hospital Social Service}

Arrangements for Convalescence.-In so far as convalescence implies merely an extension of hospital treatment in a modified form, it is a medical rather than a social need, but some degree of social supervision is desirable when arrangements for it are made. Routine convalescent treatment at cottage hospitals or local recovery units was arranged for thirty-six (12 per cent.) of the civilian patients, and in few instances did the special circumstances of the illness present difficulties. A young woman recovering from puerperal sepsis who needed to take her baby with her was the only one for whom a vacancy could not be obtained. An elderly lady recovering from pneumonia could only be placed after much difficulty and delay, while two patients were unable to obtain the special diets which they needed. Convalescence for two other patients would have involved delay and, as satisfactory arrangements could be made for them to be looked after at home, they were sent home instead.

Complaints of any sort by the patients were extremely rare, and the contrast in this respect with the previous follow-up is surprising. In the previous series a widespread dissatisfaction with facilities for convalescence was noted which was not confirmed this time. The reasons for this difference are not fully clear. Local cottage hospitals had been used as extensively as before and, although the large Red Cross convalescent home for women offered better facilities than had been available previously, it was sixteen miles from Oxford and distance from home had been a common complaint in the earlier series. Although this suggestion can only be put forward tentatively, the fact that the almoner always had an opportunity to discuss the arrangements for convalescence with these patients in advance may have had some effect on their subsequent attitude. Some patients would have preferred to remain in the hospital ward, some would rather have gone home at once, and others who wished to be sent to a particular district or convalescent home had for various reasons to be sent elsewhere; all agreed, however, after the difficulties had been fully discussed with them, that it was in their interests to take advantage of the facilities, and they went prepared to make the best of the situation, even when they would have preferred something different. It is possible that they would have settled down less happily if they had felt that they were being disposed 
of for the hospital's convenience, that convalescence was really quite unnecessary, or that they could and should have been sent nearer their own homes. Examples of all these attitudes were discovered and dealt with in the present series before convalescence was arranged, and the results of the previous follow-up suggest that insufficient attention to them caused the refusal of some patients to accept convalescent treatment and the dissatisfaction with it of others.

Three patients were sent to distant convalescent homes, and here the problem was somewhat different: a complete change of surroundings in a congenial atmosphere was a primary recommendation, and two of the patients had already left the ward. Particular care was taken to choose the home which seemed most likely to suit the temperament of the individual patient.

Chronic Institutional Care.-Only six of the patients needed chronic institutional care and for three of them satisfactory arrangements could be made. Two adult patients who had to be transferred to public assistance institutions were acutely dissatisfied, and a boy of thirteen who was dying of lymphosarcoma of the lung presented a particularly difficult problem. The numbers are too small to justify any general comment, and these examples merely illustrate a defect in our present services which is already well known. Social supervision is especially necessary when arrangements are made for patients with incurable illness who may have to remain under institutional care for the rest of their lives, but an almoner can do little to ease the situation when there is no satisfactory accommodation available.

Transport.-The difficulty of obtaining transport to and from hospital is often a serious one for patients, especially those living in country districts, and we were fortunate in having at our disposal the services of the W.V.S. Volunteer Car Pool throughout the period covered by this survey. Car journeys were arranged for fifty-three (17 per cent.) of the patients; nine patients needed more than one journey, and most of these attended hospital by car over a considerable period. About a third of the single car journeys were to destinations outside the hospital area, some of them as far distant as Exeter or Chester. Since at that time the service was entirely free and, except in rare instances, the journeys could be arranged with a minimum of time and trouble, car transport ceased almost to be thought of as a serious problem, but the previous follow-up provided examples of patients who on account of travelling difficulties had been unable to receive medical treatment or supervision which they needed.

Constant vigilance was necessary to make sure that the W.V.S. service was not abused. This is equally necessary with the present Hospital Car Service, and added work is involved in meeting the cost of the journeys, for which the hospital has'now to be responsible. Only a few ambulance journeys were arranged directly by the hospital, apart from routine convoys to the two large convalescent homes, as most of the cottage hospitals make their own arrangements with local ambulance services. The expense of local ambulance journeys did not cause much difficulty, but two patients who had to be sent for long distances by ambulance required substantial help with the cost. 


\section{Adequacy of Hospital Social Service Provided}

An attempt had been made to provide hospital social service for all the patients in the second series and to continue social supervision after discharge for such patients as needed it, but it remained uncertain until the second follow-up had been completed whether, in fact, the service provided had been adequate. The results obtained were satisfactory in this respect. In the earlier follow-up it was estimated that, while 20 per cent. of the patients had received some form of hospital social service, nearly 50 per cent. more should either have been helped by an almoner or referred by her to some other social agency, and 12 per cent. still presented some acute social need at the end of a year. When the second follow-up was carried out (between one and two years after the patients' admission) only six patients ( $2 \cdot 3$ per cent.) were found to have medical social problems for which further help was required and there was no evidence that any of the other patients had at an earlier stage been in need of help from the almoner which they had not received.

Of the six patients who needed further assistance, one was in general financial difficulties, two needed help in obtaining extra milk, and three were fit for work but not employed. The social welfare of the first patient was no longer strictly speaking our responsibility, as he had by then moved to London and was under the care of another hospital; much the same applies to one of the patients needing extra milk who had previously been referred to the tuberculosis authorities for further supervision. One of the patients who wanted work had only spent one night in hospital and had not been seen by the almoner; in any case he was over sixty-five and the possibility of getting him suitably placed was doubtful. Attempts had already been made through the Ministry of Labour to find suitable work for one of the other patients and the lack of an adequate bus service near his home had proved the main stumbling block; as he had other sources of income and was well occupied at home, no further action had been taken. The last patient could have been helped to find work sooner if his need had been discovered, but he was a man of low mentality and had not responded to a written follow-up enquiry.

The residual medical social problems discovered were not only numerically smaller but also individually less serious than those disclosed by the previous follow-up and, although the proportion of patients who required social supervision appears to have been rather higher in the earlier series, this would not be sufficient to account for the difference in the final results. The value of the advice given to patients who needed no material assistance and for whom no serious difficulties arose cannot easily be determined, but it is possible that potential problems were prevented by this means. For instance, the failure of some patients to obtain certain statutory benefits to which they were entitled, especially when they became involved in the complexities of national health insurance procedure, was commented on by the writers of the previous report; eligibility and methods of application were a frequent subject of enquiry among patients in the present series, and it is satisfactory to note that, with the exception of two (both of whom had been offered 
further help if they had cared to avail themselves of it), all the patients who were entitled to such benefits had received them.

\section{Methods of Hospital Social Service}

Patients in the present series were interviewed briefly by the almoner as soon as possible after admission in order to find out whether any immediate help was required and to get a rough idea of what problems might arise if the illness should prove to be a long and serious one. Patients admitted from the waiting-list had usually been seen already by the almoner in the out-patient department, and sometimes her assistance had been needed in making arrangements for admission.

As soon as the medical staff were able to state the probable prognosis and general recommendations for treatment and after-care, patients who were likely to have social difficulties were interviewed again at greater length and at this point the relatives were, if necessary, seen as well. Every effort was made to ensure that any necessary medical information had already been given by the medical staff. Often it was found that patients " hadn't liked to ask," and relatives were particularly diffident about " bothering the doctors." When the patients or relatives had been told as much about the illness as the medical staff considered advisable, the almoner could proceed with the task of ensuring that any necessary social adjustments could and would be carried out.

It is, of course, a fundamental principle of social case-work that individuals should be encouraged to make the fullest use of their own resources and those of their families. Patients who thought their difficulties insurmountable were sometimes able to find their own solution once they had been helped to face the issue clearly, and, even when material assistance was needed, it was provided as part of a general plan to restore the patient to independence as soon as possible.

The amount of work required varied according to the type of service needed. The subsidiary services, which were required most frequently, seldom involved any great expenditure of time. Provision of routine convalescent treatment may be quoted as an example: for this, the necessary information had to be given to the matron of the convalescent home and certain other routine details completed, the patients were seen and the arrangements discussed with them, and the ward was finally notified when the vacancies were obtained. Where special diets or other requirements made it more difficult to find a suitable vacancy, more detailed work might be needed, and for one elderly lady with bronchopneumonia eight telephone conversations, seven interviews with the patient or her relatives, a visit to her brother's home, and consultations with the medical staff were necessary before the matter could be satisfactorily settled.

Provision of material assistance required correspondence or telephone conversations with outside agencies as well as interviews with the patients concerned, while contact between almoner and patient over a considerable period might be needed when personal problems were involved. The amount of time required 
generally depended less̀ on the gravity of the individual problems than on the number of different ones found together. The more complex the network of interdependent problems-personal, financial, occupational and domestic-the longer the time required to unravel them. Only twenty-seven patients required intensive social case-work, but the amount of time spent on them was considerable. The work involved for one of these patients who represents an average sample was spread over a period of five months and included thirteen detailed interviews with patient or relatives and one with a Ministry of Labour official, three visits to the patient's home, six letters, and five consultations with the medical staff, in addition to shorter conversations with the medical and nursing staff which were not recorded.

\section{STAFFING REQUIREMENTS}

The earlier report indicated that the almoner's department had not been able to supply more than 30 per cent. at most of the hospital social service required. At that time there were only three trained almoners for a hospital of 500 beds, and they were in addition considerably burdened with routine duties unconnected with medical social work. It appears from the results recorded here that the social supervision of the second series was adequate, and on this basis the amount of almoning time needed to provide such a service can be discussed. The time which the almoner required for this work depended largely on the complexity of the problems and on the type of service required, but the proportion of patients whose assistance involved numerous interviews and home visits or long correspondence was relatively small (see Table). The almoner concerned was also engaged on other work, and the number of hours spent on each varied from time to time, but the experience gained suggests that to provide adequate hospital social service for medical patients a ratio of two almoners to 100 beds and the corresponding outpatient clinics would be sufficient. This assumes, however, that the almoners would not be responsible for assessment and other such administrative duties, and that they would have sufficient clerical help, i.e. one secretary for the two almoners.

\section{Co-operation with the Medical Staff}

The opportunity for close contact with the medical staff while undertaking the work discussed here was an immense advantage to the almoner in her work. Attendance at the weekly departmental staff meeting enabled her both to obtain advice about the after-care of individual patients and to report what had happened to them at a later date, and also to discuss matters of general policy affecting her work. At a later period than that covered here, a weekly ward round was instituted at which all the medical staff of the unit were present and which the almoner was invited to attend; this has proved a valuable additional means of keeping in touch with what is being done for patients on the medical side and of discovering any social implications of their illness at an early stage. 
The suggested ratio of two almoners to 100 beds, with out-patient clinics in addition, would not allow for as much time spent on the ward as was possible here, and it would be necessary to rely to a greater extent on referral to the almoner by the medical staff of patients who required her help. It was noticed in the present series that some of the patients who developed the most serious problems were those who had not been referred to the almoner for assistance, and valuable time would have been lost if they had not been referred till later when their problems became more apparent. Experience gained here strengthens the conviction that the essence of constructive medical social work is to start treating potential problems before any obvious social complications have had time to develop. It is therefore suggested that, in addition to the patients whose need for social service has been noted by the medical staff, or for whom social investigation might be useful for diagnostic purposes, the almoner's attention should be drawn at the earliest opportunity to all patients $(a)$ who are unlikely to return to full activity within three months, (b) who will need to modify their normal life, whether in respect of employment, dietary habits, or in other ways, or $(c)$ who, for no very obvious reason, have not settled down happily in hospital or are unwilling to carry out the medical recommendations.

\section{ConClusion}

It would be unwise to stress unduly the general implications of a limited survey; the difficulty of defining social problems and the complex network of personal and material factors that give rise to them make any attempt at statistical analysis dangerous, and the figures quoted here should be regarded as no more than a rough approximation. In any case, temporary conditions such as full employment and high wages must have affected the results to some extent, while in addition allowance must be made for local factors such as a high standard of thrift and self-reliance which is characteristic of an area that still retains many of its rural traditions. The general conclusions reached are, however, in keeping with the experience of other almoners, and it is hoped that they may be of some use as an indication of the extent to which hospital social service is needed for medical patients and of the way in which it may be provided.

\section{SUMMARY}

1. Over 50 per cent. of patients in a medical ward needed some form of social service.

2. The most serious problems were loss of wages, necessity to change employment, and domestic difficulties.

3. Comparison with a previous survey suggests that the essence of constructive medical social work is to start treatment of potential problems before obvious social complications have had time to develop. 
4. The almoner's attention should be drawn to all patients who are unlikely to return to full activity within three months, all who will need to modify their employment, diet, or other ways of life, and all who have not settled down in hospital or agreed to carry out the medical recommendations.

5. A ratio of two almoners to 100 beds and the corresponding out-patient clinics should be adequate for social service of the kind described.

\section{REFERENCE}

Brown, M., and Carling, F. C. Brit. med. J., 1945, 1, 478.

\section{APPENDIX}

DETAILS OF SOCIAL SERVICE PROVIDED

\section{Personal Assistance}

Total number of patients helped

Help given included:

Help in adjustment of emotional difficulties $\quad 14$

Long-term planning and supervision

Discussions of practical social implications of medical recommendations

Advice on other minor problems

(55 patients in this series also required some form of material assistance.)

\section{Material Assistance}

Total number of patients helped

Help given included:

Help in obtaining change or adjustment of employment 24

Financial assistance

Help with domestic difficulties

Transport

Convalescence

Help in obtaining special diets

Accommodation for relatives

Miscellaneous minor services

Total number of patients in series

\section{PROPORTION OF PATIENTS REQUIRING SOCIAL SERVICE}

(Excluding 20 service patients with infective hepatitis, 7 other service patients in hospital for periods of less than three weeks, and 17 civilian patients with infective hepatitis, 6 of whom required transport.)

Patients with serious social problems requiring detailed and long-term case work .. $\quad . . \quad$ Per cent.

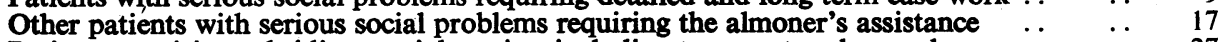
Patients requiring subsidiary social service, including transport and convalescence $\quad \ldots .27$

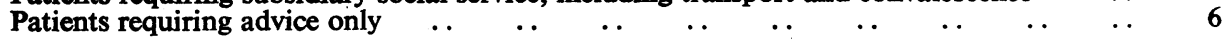

Toral $\quad \ldots \quad \overline{59}$ 